\title{
Why and How the Value of Science-Based Firms Violates Financial Theory: Implications for Policy and Governance
}

\author{
Sergey Bredikhin ${ }^{\text {a }}$ \\ Junior Research Fellow, Centre for S\&T, Innovation and Information Policy, Institute for Statistical Studies and \\ Economics of Knowledge (ISSEK), sbredikhin@hse.ru \\ Jonathan Linton b; a \\ Head of Operations and Technology Management, School of Management; Head of Laboratory, Research \\ Laboratory for Science and Technology Studies, ISSEK, j.linton@sheffield.ac.uk
}

\section{Thais Matoszko ${ }^{c}$ \\ Graduate Student, thais@itamambuca.com.br}

${ }^{a}$ National Research University Higher School of Economics, 11 Myasnitskaya str., Moscow 101000, Russian Federation

${ }^{\mathrm{b}}$ University of Sheffield, B067, Conduit Road, S10 1LF, UK

c Universidade Federal de São Carlos, Rodovia Washington Luís, 310, São Carlos - SP, Brasil.

\begin{abstract}
$\mathrm{T}$ This paper considers how and why the positive net effect of science-related activities substantially increases the value beyond what would be anticipated by the financial theory, which seems to work so well for other fields. A qualitative analysis of 25 small biotechnology R\&D firms listed on a stock exchange illustrates that these firms do not follow the neo-classical expectation of Gaussian returns. To better understand this deviation from the expected Gaussian returns, the firms are compared to S\&P 100 and the Thomson Reuters Global Innovator List. It is found that while these large firms have

a higher than expected frequency of non-Gaussian events, the causes appear to be dominated by macro-economic or industrial events that impact a large number of firms. With the small R\&D-intensive biotechnology firms, it is possible to identify specific events that appear to trigger a sudden increase or decrease in value. A better understanding of the nature and magnitude of these events allows policy makers, investors and managers to better comprehend the unusually large risks and new opportunities associated with biotechnology R\&D. From this, a greater insight is afforded into the dynamic value of $\mathrm{R} \& \mathrm{D}$ in general.
\end{abstract}

\section{Keywords:}

firm value;

biotechnology R\&D;

financial theory;

volatility of market value;

R\&D intensive firms.

Citation: Bredikhin S., Linton J., Matoszko T. (2017)

Why and How the Value of Science-Based Firms Violates Financial Theory: Implications for Policy and Governance. Foresight and STI Governance, vol. 11, no 1, pp. 24-30. DOI: 10.17323/2500-2597.2017.1.24.30. 
$\mathrm{T}$ his paper considers how and why R\&D-intensive smaller firms have significant differences in financial return behavior [Casault et al., 2013, 2014] than from what is expected based on the prevailing neo-classical economic theory [Willigers, Hansen, 2008; Newton et al., 2004]. Our paper is dedicated to exploring the nature of such contradictions and why they may appear. While the focus of this paper is on the direct impact of research-related activity, information is provided on events that are both related and unrelated to research activity. In doing so, a general understanding of non-equilibrium behavior is offered, while providing deeper insights into the impact of science, technology and innovation on $R \& D$ intensive organizations.

While it is relatively well-known that strong uneven fluctuations in the marginal distribution of returns can arise as a result of pure randomness [Filiasi et al., 2014], the herding behavior of investors is also considered a general mechanism behind speculative bubbles [Sornette, Ouillon, 2012; Wosnitza, Sornette, 2015]. In the case of R\&D-intensive firms, however, innovation activity results could potentially serve as a common trigger for such 'herding' dynamics. To clearly understand how the behavior of R\&D intensive firms is similar and different from other firms, consideration is given to the $76 \mathrm{~S} \& \mathrm{P} 100^{1}$ firms that are not on the Thomson Reuters Global Innovator List ${ }^{2}$ to obtain an indication of baseline behavior for large, successful firms. Next, the 83 companies on the Thomson Reuters 2013 Global Innovator List are considered (this list includes 24 S\&P100 firms and 59 other large international firms).

To test our hypothesis that R\&D activity is an important driver of sudden increases (and decreases) in share value, the average daily number of financial market events ( $>3 \sigma$ price changes) is considered for large innovative and less innovative firms over the period of 2003-2013. The proportion of each of these groups having a number of $>3 \sigma$ price changes is shown for each day in Figure 1. An examination of the S\&P 100 firms that were not noted by Thomson and Reuters as innovators (blue line) demonstrates a large number of non-Gaussian events. In fact, it is easy to obtain the impression that the less innovative large firms (blue line) experience more non-Gaussian events than the more innovative firms (red line). A careful examination of the occurrence of common dates for sudden changes in market value found that many firms were experiencing sudden changes on exactly the same date. As such a co-occurrence is potentially explained by macro-economic factors, further consideration was given. This assessment is perhaps best summarized and simplified through the consideration of Figure 2 - the share of firms with a value change greater than $3 \sigma$ without considering years 2008, 2009 and 2011 that were removed from consideration. Removing these years eliminates the impact of major macroeconomic events, such as the stock market crash and concerns regarding Greek and US debt and budgets. Removing these three years of tremendous economic volatility eliminates the dominance of the less innovative large firms (blue) from Figure 2. Now the more innovative firms (red), dominate the less innovative firms on the majority

Figure 1. The daily average of a number of $>3 \sigma$ price changes over the period of 2003-2013 by the day of the year

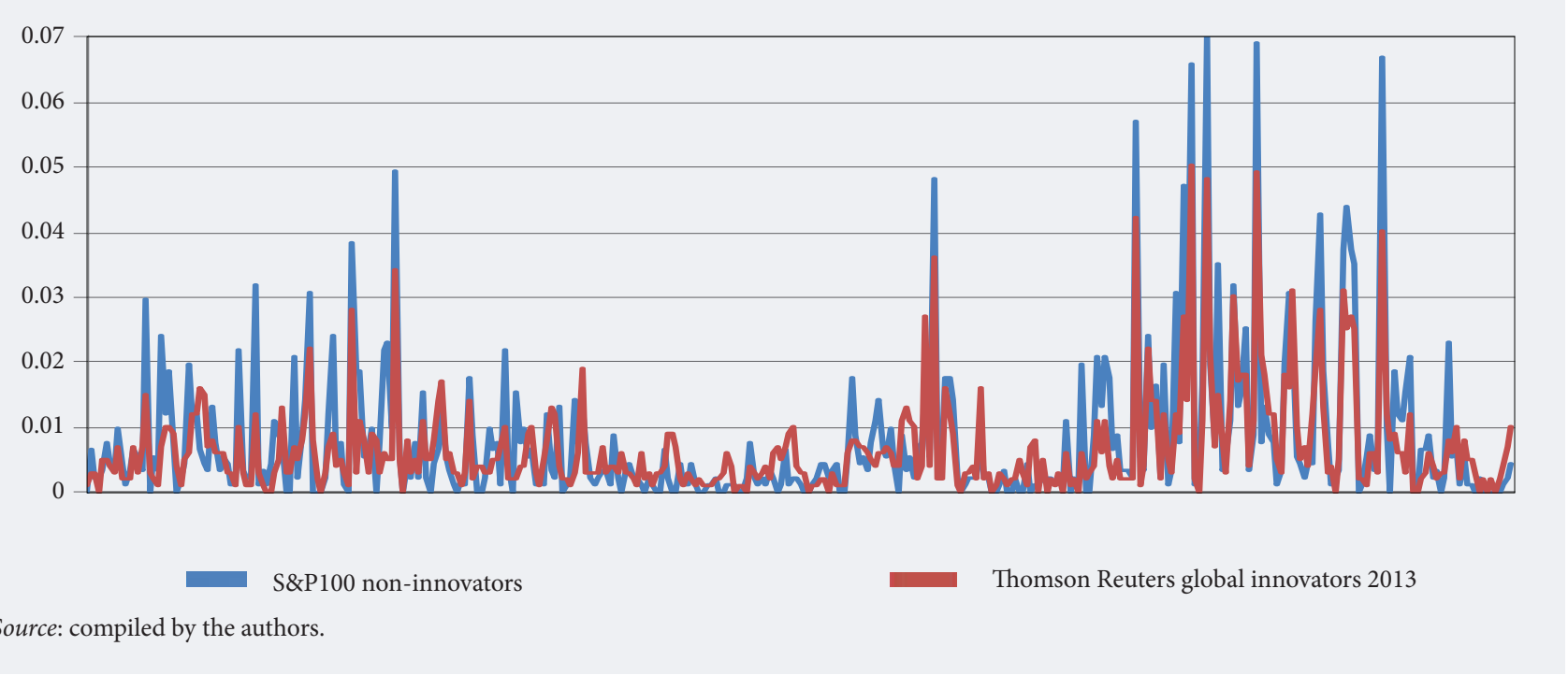

\footnotetext{
Available at: http://us.spindices.com/indices/equity/sp-global-100-c, accessed 17.08.2016.

Available at: http://www.reuters.com/bizfinance/technology/Top100Innovators, accessed 17.08.2016.
} 


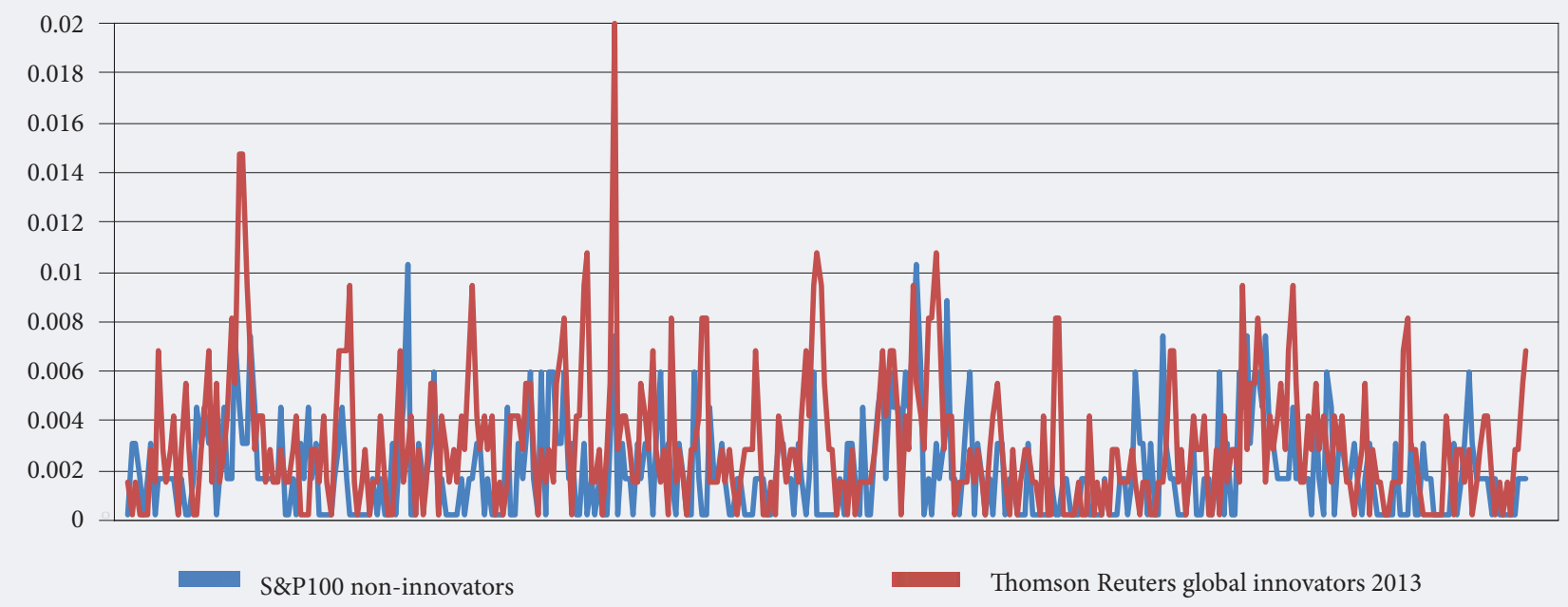

Source: compiled by the authors.

of days. The correlation between the share of volatile events as a function of time for more-innovative and less-innovative large firms falls from 0.87 to 0.24 - between Figures 1 and 2 . The important conclusion from Figures 1 and 2 is that more innovative large companies are strongly dependent on the rest of the economy; prices move in a coherent manner during the times of powerful exogenous shocks, less strongly otherwise.

Having considered larger innovative firms' sudden changes in value, focus is now shifted to the smallest most R\&D-intensive biotechnology firms. This group has been chosen as an example, because the smallest listed firms are likely to be based on one technology product or platform. Consequently, there should be no portfolio effect dampening the impact of favorable or unfavorable science, technology and innovation-related events. Furthermore, the value of biotechnology firms is heavily associated with intellectual property (IP). The presence or absence of real estate holdings or manufacturing facilities is unlikely to make a significant difference in day-to-day market valuation. Firms were also selected based on the presence of sufficient external media coverage so that one could determine the nature of events that appear to cause a sudden change in price (i.e., when an event and a sudden dramatic change in price coincide). This requirement reduced the number of appropriate small R\&D intensive firms from 52 to 25 . Over the period of 2003 to 2013, these firms experienced 20 events with daily price changes of greater than $8 \sigma$, although the chance of a single event occurring above this level during this period is less than one out of $10^{11}$. If we consider smaller but still uncommonly large daily price changes $(3 \sigma-8 \sigma)$ there are 663 events instead of the 69 expected by financial and statistical theory. By understanding the nature of these events, insights into how R\&D intensive biotechnology firms are unique are offered. It is likely that these results could be applied to other industries. However, in industries where IP and regulations such as FDA trials plays a lesser role in firm value, it may be more challenging to isolate the impact of science, technology and innovation on a firm's value. A search of company websites and Business Wire ${ }^{3}$ allowed for the identification of announcements that explained the unexpected extreme financial behavior for 295 (44\%) of these dates.

\section{Biotechnology R\&D and Thick Tails: Empirical Evidence}

As daily changes in price increase in magnitude, the frequency of occurrence should decline exponentially. While the occurrence of large changes in price drop-off quickly, the decline is slower than anticipated (see Table 1). This is important as R\&D intensive biotechnology firms have large price change events many orders of magnitude greater than expected. In terms of investing, this suggests that a portfolio consisting of these R\&D intensive small biotechnology firms will have a series of unexpected large

Available at: http://www.businesswire.com/portal/site/home/, accessed 23.06.2016. 
Table 1. Summary of the frequency of high variability change and the difference in order of magnitude between theoretically anticipated and empirical occurrence ${ }^{\star}$

\begin{tabular}{|l|l|l|}
\hline \multicolumn{1}{|c|}{$\begin{array}{c}\text { Magnitude of Price } \\
\text { Change }\end{array}$} & \multicolumn{1}{c|}{$\begin{array}{c}\text { Number of Events in 25 Firms } \\
\text { Under Consideration }\end{array}$} & $\begin{array}{c}\text { Difference in Actual versus Difference in } \\
\text { Expected Occurrence (order of magnitude) }\end{array}$ \\
\hline Under $-8 \sigma$ & 32 & $12+$ \\
\hline From -7 to $-8 \sigma$ & 10 & $7+$ \\
\hline From -6 to $-7 \sigma$ & 7 & $4+$ \\
\hline From -5 to $-6 \sigma$ & 18 & $2+$ \\
\hline From -4 to $-5 \sigma$ & 55 & $1+$ \\
\hline From -3 to $-4 \sigma$ & 128 & $0(1.4$ times) \\
\hline From 3 to $4 \sigma$ & 239 & $0(2.6$ times) \\
\hline From 4 to $5 \sigma$ & 84 & $1+$ \\
\hline From 5 to $6 \sigma$ & 37 & $3+$ \\
\hline From 6 to $7 \sigma$ & 17 & $5+$ \\
\hline From 7 to $8 \sigma$ & 9 & $7+$ \\
\hline Over $8 \sigma$ & 27 & $12+$ \\
\hline * For example if an event should occur 1 in a 1,000 times, but is occurring 2 in 10 times - the order of magnitude is $2+)$. \\
Source: compiled by the authors. \\
\hline
\end{tabular}

magnitude events that will contribute to a net positive change of over $600 \sigma$. As financial theory suggests, the distribution of change is symmetrical around 0 , this finding is unexpected and important. While theoretically unexpected, this positive performance is consistent with the strong market performance of firms that are based on research in biotechnology.

Sudden unexpected changes in price for biotechnology research-based firms have both managerial and technical drivers. While the managerial drivers are of interest to investors and managers, the technical drivers are important to scientists and policy makers as they offer insight into how the value of research can soar and plummet as the result of a single event. As some suggest that research should be managed like other investments, evidence that the behavior of science differs greatly from other investments is critical to prevent high-risk, high-value research from being discarded by the Generally Accepted Practices and Principles of accountants and other investment analysts. Consequently, both managerial drivers and technical drivers are reported (Table 2).

However, this article focuses on the implications of the technical drivers to theory and practice. Onehundred and forty-six of the extreme events are related to the underlying science and technology in some way - trial results, FDA approval, new discovery/use, science-related conference calls or agreements and patents. The net impact of these science-related changes for firm value is equivalent to $108 \sigma$ (Figure 3). Changes in value can be either positive or negative. The failure of an experiment may wipe out value equivalent to over $22 \sigma-$ a change so large it eliminates all or almost all of the host firm's value. Similarly, a successful experiment can add tremendous value $(23 \sigma)$ and the identification of a new use or product can add over 13б. Sudden events having values of this magnitude are unheard of in effective financial market theory and consequently suggest that the rules of the game in biotechnology are different. In effect, it makes such an event a potential candidate as a so-called "dragon-king". Dragon kings are extreme events of higher frequency than expected by power-law scaling occurrence that do not belong to the same classification as the other events [Sornette, 2009], rather than as the inherently unpredictable class of "Black Swans" [Taleb, 2007]. This type of dragon-king can be exemplified by the 'lucky villager' metaphor, when one of the village residents hits the jackpot in the national lottery and this results in creating an outlier compared to the statistics of players' wins provided by local gambling houses [Malkov et al., 2012]. However, further research and adequate statistical tests are needed to diagnose a dragon-king in the sample and thus assess the degree of predictability [Sornette, Ouillon, 2012] of R\&D-driven value changes. In the meantime, they should be treated as purely stochastic phenomena. This being the case, it is worth considering these implications for decision support and managing biotechnology research.

\section{Implications for Decision-Making and Management of Biotechnology R\&D}

As suggested earlier, the management and investing side is acknowledged and included in the table, but the article itself is focused on the implications of the extraordinary events for assessing and managing the 
Table 2. Summary of the science and managerial related reasons for large sudden shifts in firm value *

\begin{tabular}{|c|c|c|c|c|c|c|c|}
\hline \multirow{2}{*}{$\begin{array}{l}\text { Type of Event associated to } \\
\text { Jump in Firm Value }\end{array}$} & \multicolumn{3}{|c|}{ Occurrences Identified: } & \multicolumn{2}{|c|}{ Extrema $(\sigma)$} & \multicolumn{2}{|c|}{ Average ( $\sigma)$} \\
\hline & total & positive & negative & positive & negative & positive & negative \\
\hline Trial Result & 81 & 45 & 36 & 23.0 & 22.1 & 5.1 & 7.3 \\
\hline FDA Announcement & 38 & 21 & 17 & 21.9 & 9.3 & 5.8 & 5.7 \\
\hline $\begin{array}{l}\text { New Discovery/ Product } \\
\text { Release }\end{array}$ & 19 & 14 & 5 & 13.8 & 5.3 & 6.9 & 3.9 \\
\hline $\begin{array}{l}\text { Conference Call - } \\
\text { re Science }\end{array}$ & 7 & 4 & 3 & 4.7 & 7.1 & 3.5 & 4.8 \\
\hline $\begin{array}{l}\text { Third Party Agreement - } \\
\text { re Science }\end{array}$ & 8 & 6 & 2 & 13.6 & 4.6 & 7.1 & 4.0 \\
\hline Patent Granted & 3 & 3 & & 3.9 & & 1.7 & \\
\hline Financial Result Published & 40 & 23 & 17 & 8.8 & 18.8 & 4.3 & 5.6 \\
\hline Common Stock Issued & 24 & 9 & 15 & 22.5 & 24.5 & 7.7 & 7.4 \\
\hline Financing Announcement & 17 & 11 & 6 & 5.2 & 6.0 & 4.9 & 4.1 \\
\hline $\begin{array}{l}\text { Conference Call - } \\
\text { re Management }\end{array}$ & 12 & 8 & 4 & 6.1 & 4.0 & 4.3 & 3.6 \\
\hline $\begin{array}{l}\text { Third Party Agreement - } \\
\text { re Management }\end{array}$ & 8 & 6 & 2 & 17.8 & 8.9 & 7.0 & 6.3 \\
\hline $\begin{array}{l}\text { Change to Management } \\
\text { Team }\end{array}$ & 12 & 9 & 3 & 5.4 & 12.1 & 7.0 & 6.3 \\
\hline Court Announcement & 5 & 4 & 1 & 4.0 & 3.1 & 3.7 & 3.1 \\
\hline International Agreements & 10 & 8 & 2 & 5.0 & 4.5 & 4.3 & 4.1 \\
\hline $\begin{array}{l}\text { Acquisition of } \mathrm{New} \\
\text { Equipment }\end{array}$ & 1 & 0 & 1 & & 3.1 & & 3.1 \\
\hline Public Offering & 7 & 2 & 5 & 8.4 & 6.5 & 8.3 & 5.4 \\
\hline Change of Firm Name & 1 & 1 & 0 & 5.7 & & 5.7 & \\
\hline New Strategy Announced & 1 & 1 & 0 & 18.6 & & 18.6 & \\
\hline \multicolumn{8}{|c|}{$\begin{array}{l}{ }^{*} \text { Frequency, extrema, and averages - for positive and negative events - are all expressed in terms of standard deviation of share } \\
\text { price }(\sigma) \text {. }\end{array}$} \\
\hline
\end{tabular}

underlying science. The extreme and sudden shifts in value that can occur when a scientific experiment succeeds or fails call for different approaches to management. The consideration of single experiments or discoveries should be replaced with a consideration of portfolios. Otherwise, managers and analysts will tend to make decisions against projects with high potential - as failure can lead to a tremendous and sudden loss in value. What is also apparent is that a single extremely valuable discovery is not proof of brilliance; nor is an extreme failure a sign of incompetence. While scientists should be acknowledged for their successes, it is the portfolio results that are telling with regard to the quality of the scientist. It is critical that scientists who experience significant failures not be discouraged from taking on significant challenges as one or more large magnitude failed experiments do reflect the willingness of the scientist to conduct high risk/high return research, but not their ability to do so.

To some extent, the shift to portfolios has already commenced. The occurrence of taking partial stakes in a larger number of projects and risk sharing with competitors, supply chain members and other stake holders continues to increase. The Bayh-Dohl Act in the United States supports the ability to conduct research in this manner. Other social innovations should be devised to enable and support risk sharing, consortia building, and technology transfer.

To better model expectations and the value of biotechnology research, the behavior of research-intensive biotechnology firms (such as the sample of the 25 firms considered here - Table 3) should be considered and methods such as Monte-Carlo resampling can be used to determine the potential outcomes of research. To approximate the added value of unexpected large price change events for a portfolio of research, we consider our sample of 25 firms, together they offer a surplus of $108 \sigma$. If we assume that the firms have a mean value of 100 and a $\sigma$ of 10 , traditional financial analysis would consider no surplus over the mean value of $100-$ as the symmetry around the mean results in the value equaling the mean. However, as there is an asymmetrical surplus of $108 \sigma$ (Figure 3) - corrected for $25 \mathrm{firms}$, it is equivalent to $4.32 \sigma$. The value of the portfolio is equal to the product of the mean and the asymmetry $(4.32 \times 10)=143.20$. Consequently, recognizing the net positive effects associated with the uncertainty related to the science increases the value by $43.2 \%$ in this illustration of results from a portfolio of $25 \mathrm{R} \& \mathrm{D}$ intensive biotechnology firms. 


\section{Figure 3. Visual summary of impact of extreme science related events and how they move the value of the portfolio of biotechnology firms away from and above the expected mean price}

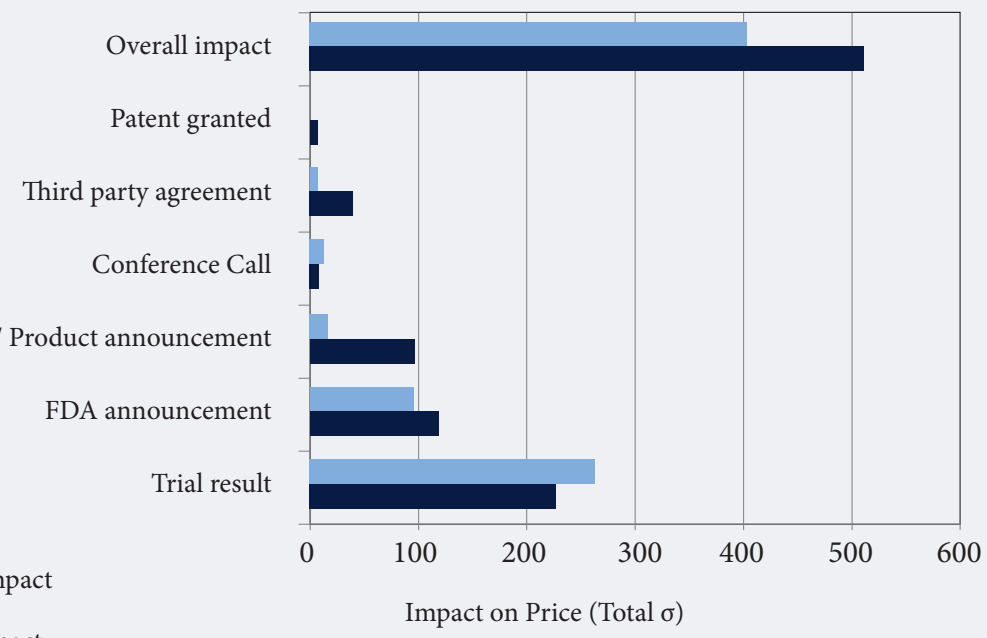

Source: compiled by the authors.

\section{Table 3. R\&D Intensive Biotech Firms that made up the sample}

\begin{tabular}{|c|c|c|}
\hline Company Name & Activities & Location \\
\hline ACADIA pharmaceuticals Inc. & Noncommercial Research organization & San Diego, CA \\
\hline Access Pharmaceuticals Inc. & Commercial Research Laboratory & Dallas, TX \\
\hline Adolor Corp & Pharmaceutical Preparations & Lexington, PA \\
\hline Alexza Pharmaceuticals Inc. & Pharmaceutical Preparations & Moutain View, CA \\
\hline Ap Pharma Inc. & Pharmaceutical Preparations & Redwood City, CA \\
\hline Aastrom Biosciences Inc. & Medical Labs & Ann Arbor, MI \\
\hline Athersys inc. & Pharmaceutical Preparations & Cleveland, $\mathrm{OH}$ \\
\hline Cyclacel Pharmaceuticals Inc. & Research and Development Laboratories & Berkeley Heights, NJ \\
\hline Elite Pharmaceuticals Inc. & Pharmaceutical Research Labs & Northvale, NJ \\
\hline Emisphere Tech Inc. & Pharmaceutical Preparations & Cedar Knolls, NJ \\
\hline Entre Med Inc. & Pharmaceutical Preparations & Rockville, MD \\
\hline Fibrocell Science Inc. & Autologous Cellular Therapeutic Company & Exton, PA \\
\hline GenMark Diagnostics Inc. & Biotechnology Products and Services & Carlsbad, CA \\
\hline GenVec Inc. & Pharmaceutical Preparations & Gaithersburg, MD \\
\hline Hemispherx Biopharma Inc. & Biotechnology Products and Services & Philadelphia, PA \\
\hline Insmed Inc. & Pharmaceutical Preparations & Monmouth Junction, NJ \\
\hline NovaDel Pharma Inc. & Specialty Pharmaceutical Company & Bridgewater, NJ \\
\hline Northwest Biotherapeutics & Pharmaceutical Preparations & Bethesda, MD \\
\hline Oculus Innovative Sciences Inc. & Biotechnology Products and Services & Petaluma, CA \\
\hline Oncothyreon Inc. & Commercial Physical \& Biological Research & Seattle, WA \\
\hline Oxigen Biotherapeutics Inc. & Commercial Physical \& Biological Research & Morrisville, NC \\
\hline OXIS International Inc. & Pharmaceutical Preparations & Beverly Hills, CA \\
\hline Regenerx Biopharmaceuticals Inc. & Pharmaceutical Preparations & Bethesda, MD \\
\hline Virtual Scopics Inc. & Surgical and Medical Instruments & Rochester, NY \\
\hline WaferGen Biosystems Inc. & Laboratory Analytical Instruments & Fremont, CA \\
\hline
\end{tabular}




\section{Conclusions}

This study of 52 research-intensive biotechnology firms indicates a departure from the fundamental assumptions of financial theory - efficient markets and Gaussian Brownian motion. A further consideration of the sample of 25 firms that had readily available news releases for a substantial number (44\%) of the sudden large price change events found that events with a scientific base (e.g. discoveries

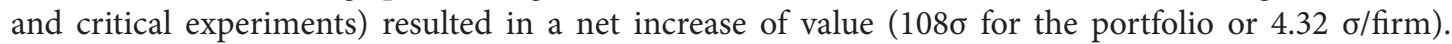
Consequently, traditional techniques such as Net Present Value (NPV), Internal Rate of Return (IRR) and simple payback to assess value will systematically undervalue and discourage worthwhile research. To assess value more appropriately it is worthwhile to model R\&D and science investment decisions for biotechnology on the behavior associated with research-intensive firms. While screening of projects is likely to be done on a project-by-project basis, evaluation and tracking should be done on a portfolio basis. Through the consideration of the magnitude of extreme events such as trial results, FDA approvals, patents and discoveries it is possible to obtain a better understanding of the impacts of scientific research and to gain a better appreciation of the real value it offers.

The article was prepared within the framework of the Basic Research Program at the National Research University Higher School of Economics (HSE) and supported within the framework of a subsidy by the Russian Academic Excellence Project '5-100'.

\section{References}

Casault S., Groen A.J., Linton J.D. (2013) Examination of the behavior of R\&D returns using a power law. Science and Public Policy, vol. 40, no 2, pp. 219-228.

Casault S., Groen A.J., Linton J.D. (2014) Improving value assessment of high-risk, high-reward biotechnology research: The role of "thick tails". New Biotechnology, vol. 31, no 2, pp. 172-178.

Filiasi M., Livan G., Marsili M., Peressi M., Vesselli E., Zarinelli E. (2014) On the concentration of large deviations for fat tailed distributions, with application to financial data. Journal of Statistical Mechanics: Theory and Experiment (online), issue 9, P09030. Available at: http://iopscience.iop.org/article/10.1088/1742-5468/2014/09/P09030/pdf, accessed 15.02.2016.

Malkov A., Zinkina J., Korotayev A. (2012) The origins of dragon-kings and their occurrence in society. Physica A: Statistical Mechanics and its Applications, vol. 391, no 21, pp. 5215-5229.

Newton D.P., Paxson D.A., Widdicks M. (2004) Real R\&D options. International Journal of Management Reviews, vol. 5-6, no 2, pp. 113-130.

Sornette D. (2009) Dragon-kings, black swans and the prediction of crises (SFI Research Paper 09-36), Zürich: Swiss Finance Institute.

Sornette D., Ouillon G. (2012) Dragon-kings: Mechanisms, statistical methods and empirical evidence. The European Physical Journal Special Topics, vol. 205, no 1, pp. 1-26.

Taleb N.N. (2007) The Black Swan: The Impact of the Highly Improbable, New York: Random House.

Willigers B.J.A., Hansen T.L. (2008) Project valuation in the pharmaceutical industry: A comparison of least-squares Monte Carlo real option valuation and conventional approaches. R\&D Management, vol. 38, no 5, pp. 520-537.

Wosnitza J.H., Sornette D. (2015) Analysis of log-periodic power law singularity patterns in time series related to credit risk. The European Physical Journal B, vol. 88, no 4, pp. 1-11. 